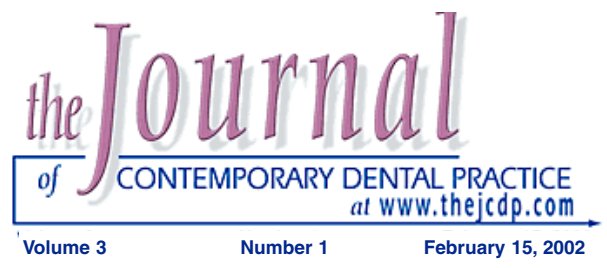

\title{
Evaluation of Apical Leakage of Root Canals Obturated with Nd: YAG Laser Softened Gutta-Percha, System-B, and Lateral Condensation Techniques
}

\author{
Murat Maden, BDS; Gũliz Gôrrgūl, BDS, PhD;
}

A. Cemal Tınaz, BDS, PhD

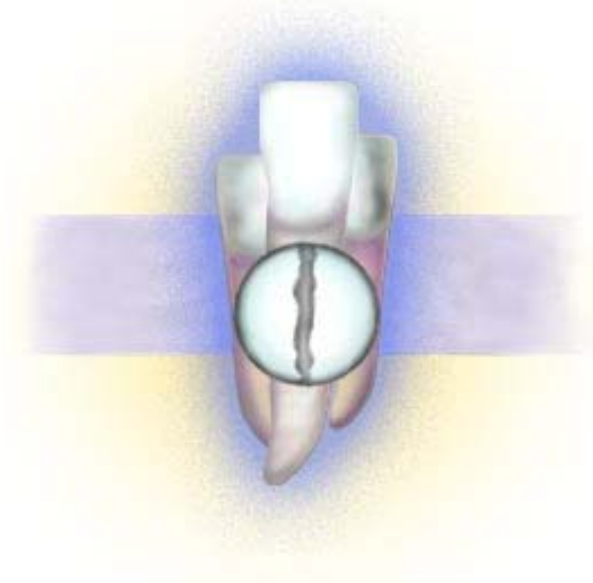

\section{Abstract}

In endodontics, a laser can be used as a heat source and gutta-percha can be softened by a laser and used in the root canals. The System-B endodontic heat source unit was designed for the obturation of the root canal system with a single continuous wave of thermoplasticized gutta-percha. The aim of this study was to compare the apical leakage of lateral condensation; Nd: YAG laser-softened gutta-percha and System-B techniques. Fifty-five extracted, single root human maxillary anterior and premolar teeth were used in this study. After working length determination, the "step-back technique" was used to prepare the root canals. The teeth were randomly divided into three experimental groups of 15 each and two control groups of 5 specimens each. The first group was obturated by lateral condensation, the second group by gutta-percha softened with an Nd: YAG laser, and the third group was obturated using the system-B technique. Apical leakage of the roots was evaluated by dye penetration using a stereomicroscope after sectioning the roots. The results of the first and third groups were similar, and the results of the second group showed differences when compared with the other groups. However, variance analysis revealed there was no statistically significant difference among the results.

Keywords: Nd: YAG laser, System-B, root canal obturation

Citation: Maden M, Görgül G, Tinaz AC. Evaluation of Apical Leakage of Root Canals Obturated with Nd: Yag laser-softened Gutta-percha, System-B, and Lateral Condensation Techniques. J Contemp Dent Pract 2002 Feb;(3)1: 016-026.

(C) Seer Publishing 


\section{Introduction}

The concept of three-dimensional cleaning, disinfecting, and shaping of the root canal system has become the major aim of modern root canal treatment. ${ }^{1,2}$ Not only are cleaning and shaping important but also sealing the root canal threedimensionally without any leakage from the apical foramen up to the coronal aspect of treated teeth. Sealing a root canal completely may increase the clinical success to a rate as high as $96.5 \%{ }^{1}$ Incompletely obturated root canal fillings will leak. ${ }^{3}$ The movement of periradicular tissue fluids, microorganisms, and their associated toxins will leak into the root canal along the interface of the dentinal walls and may lead to infection. Disseminated microorganisms, in incompletely obturated root canals, will reproduce and can migrate to the periradicular tissues and may cause irritation or inflammation. ${ }^{1,4,5}$ In endodontic practice, $60 \%$ of all the failures in root canal treatment are due to incomplete and unsuitable root canal obturations. ${ }^{1}$

Today the use of laser devices in endodontics has become popular through developments in laser technology. Dental laser uses include: pulpotomy procedures, removal of smear layers, root canal sterilization, closing dentin tubule openings, and endodontic retreatments. ${ }^{5-9}$ The laser can also be used as a source of heat, thereby, making it possible to thermoplasticize gutta-percha in order to obturate the root canal system. ${ }^{10}$

Schilder reported that vertical condensation of thermoplasticized gutta-percha could achieve a complete three-dimensional obturation of the root canal system without any potential leakage. ${ }^{11}$ The System $B$ endodontic heat source unit (EIE/Analytic Technology, Richmond, WA, USA) was designed to modify Schilder's technique by obturating the root canal system with a single continuous wave of thermoplasticized gutta-percha. Buchanan reported the root canal system could be obturated three-dimensionally in a short time with the System-B unit. ${ }^{9,11}$

The aim of this study was to evaluate the apical leakage of the teeth obturated by Nd:YAG laser softened gutta-percha, lateral condensation, and System-B techniques.

\section{Materials and Methods}

Fifty-five recently extracted human single-rooted maxillary anterior and premolar teeth with mature apices were selected and evaluated with radiographs prior to experimentation. Debris at the external root surface was scraped away using a curette. Specimens were eliminated if they had calcified canals, curvatures greater than 10-20 degrees, internal resorptions, or multiple canals.

Lingual or occlusal access cavities were made using a size ISO 012 round diamond bur in a high-speed, water-cooled handpiece. After creating access, the coronal and middle third of the canals were prepared with ISO size \#2, \#3, and \#4 Gates Glidden burs. The root canals were instrumented $0.5 \mathrm{~mm}$ short of the clinical apex with Hedström size 40 files. Root canals were irrigated with $2.5 \%$ sodium hypochlorite and $2 \%$ hydrogen peroxide after using each instrument. The final irrigation was made with a 17\% EDTA solution.

At this stage 45 teeth were randomly divided into three experimental groups (1 to 3 ) containing 15 teeth in each group. The remaining 10 teeth were divided into two control groups $(4,5)$ of 5 specimens each.

AH-26 (Dentsply De Trey GmBH Konstanz, Germany) was used in all the root canals as a sealer and ZnOE (Cavex RW Haarlem, Holland) was used to seal the coronal access of the specimens.

Group 1 - Lateral Condensation Technique: The fifteen teeth in this group were obturated by the lateral condensation technique using standardized gutta-percha cones (Dendia-Werk gmbH P.O.131, A-1239 Vienna, Austria).

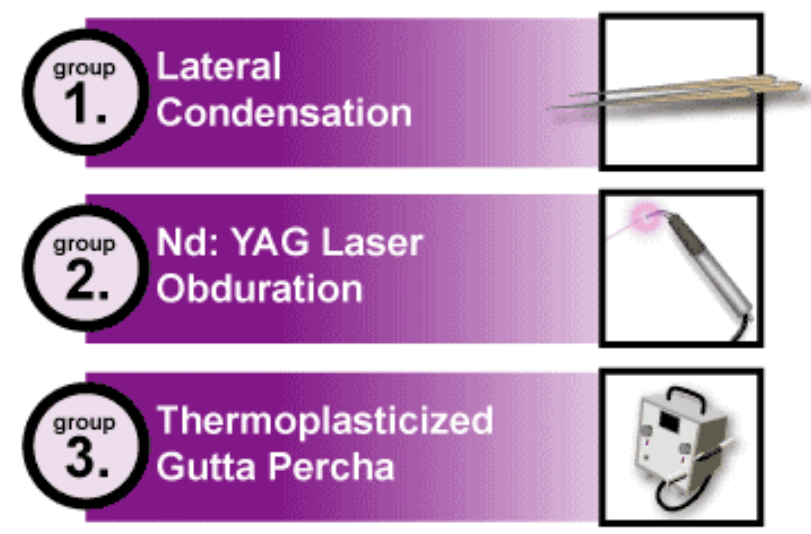

The Journal of Contemporary Dental Practice, Volume 3, No. 1, February 15, 2002 
Group 2 - Nd:YAG Laser Obturation Technique: In this group the Nd:YAG laser was used as an intracanal heat source for the sectional warm gutta-percha condensation technique. The Nd: YAG laser obturation technique was described previously by Anic and his coworkers. ${ }^{2}$ Master, non-standardized gutta-percha cone was cut into $2 \mathrm{~mm}$ long small particles using a surgical blade. The intracanal dentin walls were coated with a thin layer of $\mathrm{AH}-26$ root canal sealer using a paper point (Roeco, Langenue Germany). The apical portion of the master cone was introduced into the canal and inserted to the apical stop using a hand plugger (sizes 2 and 3, Dentsply). The optical fiber was placed into the canal $1 \mathrm{~mm}$ from the gutta-percha fragment. Then the gutta-percha fragment was lased twice with the $\mathrm{Nd}$ : YAG (pulse master $600 \mathrm{IQ}$,

American Dental Technologies, Texas, USA) laser at a pulsed wave $(60 \mathrm{mj}$, $10 \mathrm{~Hz}, 0.6 \mathrm{~W})$. Immediately after withdrawing the fiber, gutta-percha was condensed vertically using a hand plugger (a size 3 ) that was presized to fit $1 \mathrm{~mm}$ from the working length. The condensed guttapercha was lased once more and an additional gutta-percha fragment was inserted into the canal. Insertion of gutta-percha fragments, lasing, and condensation were repeated in the same manner until the desired level was achieved. The coronal canal access was sealed with $\mathrm{ZnOE}$ cement. $^{2}$

Group 3 - Thermoplasticized Gutta-percha (SYSTEM-B) Technique: Canals were obturated using System-B technique (EIE Analytic Technology Redmond, WA, USA) as recommended by the manufacturer and by Buchanan (1996). ${ }^{11}$ The canal walls were coated with $\mathrm{AH}-26$ sealer and a medium-large non-standardized gutta-percha cone was placed within $0.5 \mathrm{~mm}$ of the working length. A medium-large insert tip, which bound in the canal $3 \mathrm{~mm}$ from the working length, was used in the obturation of the canal. The System-B unit was preset to $200 \mathrm{C}$ during apical condensation of the primary gutta-percha cone (dawn-pack), to $100 \mathrm{C}$ when adapting and condensing the apical portion of the secondary (backfill) gutta-percha cone, and finally $250 \mathrm{C}$ to thermosoften the remainder of the secondary cone prior to vertical condensation. The coronal canal access was sealed with ZnOE cement.

After all the samples were checked for complete obturation radiographically, they were dried and covered with two layers of nail varnish to prevent leakage from the root surface, leaving the apical $2 \mathrm{~mm}$ uncovered. In the negative control group, the entire root surface was covered with two coats of nail varnish to demonstrate a leakage-free state. In the positive control group, no nail varnish was applied to any of the root surface.

Samples were suspended by dental floss in a closed test tube containing a $1 \%$ aqueous solution of methylene blue dye (ph 7) for 7 days at $37 \mathrm{C}$. After 7 days, the teeth were removed from the dye and rinsed with tap water for 5 minutes. Nail varnish was ablated with a curette. Teeth were bisectioned longitudinally. Sections were observed under a stereomicroscope (Olympus SZ 4045, Tokyo, Japan), and the linear extent of maximum dye penetration from the terminus of the gutta-percha was recorded with a micrometer (Canon KSM15/0.05 Nakamura Mfg. Co. Tokyo, Japan) to nearest $0.1 \mathrm{~mm}$.

Analysis of the variance was used to determine whether there were significant differences in dye leakage among the groups. Differences between means for each group were tested using Student's test. 
Table 1. Mean dye penetration values $(\mathrm{mm})$

\begin{tabular}{|l|l|l|l|l|}
\hline & Mean & SO & Min. Leakage & Max. Leakage \\
\hline $\begin{array}{l}\text { Group 1: Lateral } \\
\text { Condensation Technique }\end{array}$ & 0.267 & 0.458 & 0.00 & 1.50 \\
\hline $\begin{array}{l}\text { Group 2: Nd: YAḠ Laser } \\
\text { Obturation Technique }\end{array}$ & 0.533 & 0.442 & 0.00 & 1.50 \\
\hline $\begin{array}{l}\text { Group 3: System B } \\
\text { Technique }\end{array}$ & 0.3667 & 0.3519 & 0.00 & 1.00 \\
\hline
\end{tabular}

\section{Results}

Table 1 summarizes the mean values, standard deviations, and statistical analysis for linear dye penetration for all obturation techniques used. The positive controls showed extensive dye penetration into the root canals and dentinal tubules. The negative controls showed no dye penetration into the canal space. Among experimental groups, the most extensive dye leakage was recorded in the root canals obturated with Nd:YAG laser thermoplasticized gutta-percha. (Figure 1) The extent of dye penetration was lowest in roots obturated with gutta-percha using System-B technique. (Figure 2) The results of lateral condensation group are similar to the system-B group results. (Figure 3 ) Among the groups there were no statistical significant differences $(p<0.005)$.

Although dye penetration in group 1 and group 3 was similar and some difference was noted ingroup 2, there was no statistical difference between the groups $(p<0.05)$.

\section{Discussion}

In this study, root-canal obturations were performed using three different methods: a classic lateral condensation technique, a more recently developed low-temperature technique (System-B), and a sectional gutta-percha vertical condensation technique using laser device (Nd: YAG) as an intracanal heat source. The results showed that there was not any significant difference in the apical microleakage between the three groups. But as we look to the mean values of the groups for microleakage, there are differences among them. The lateral condensation group and the group treated with System-B showed less leakage then the group of laser-softened gutta-percha. This is in agreement with studies performed by Hata et al. ${ }^{14}$, Silver et al. ${ }^{15}$, and Greene et al. ${ }^{5}$ Microscopic and macroscopic observations revealed vertical striated but well-packed gutta-percha surfaces after lateral condensation. System-B and Nd: YAG laser thermoplasticized gutta-percha appeared to

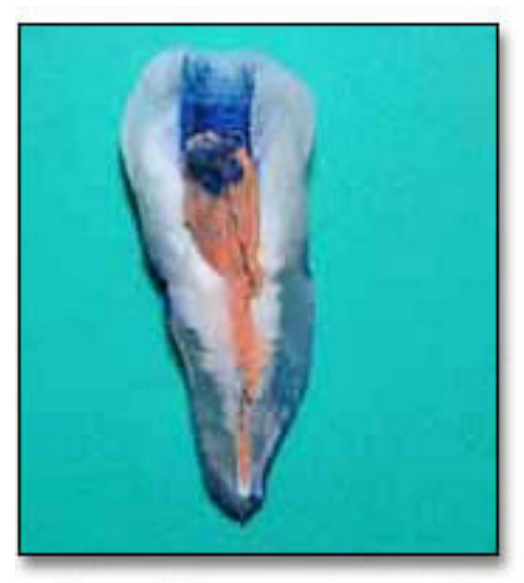

Figure 1. Dye penetration of $\mathrm{Nd}$ : YAG-softened gutta percha.

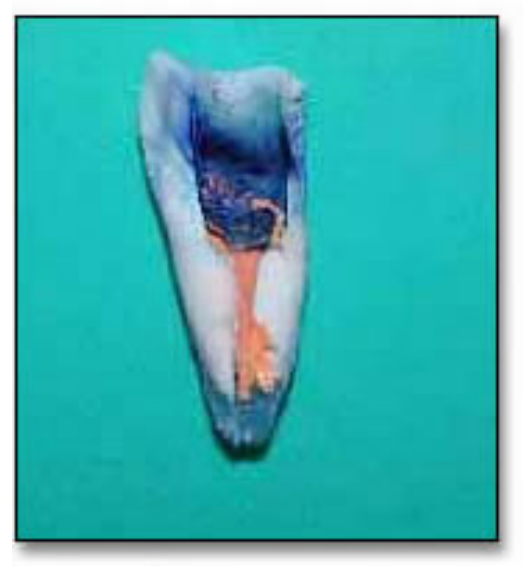

Figure 2. Dye penetration of System B treated group.

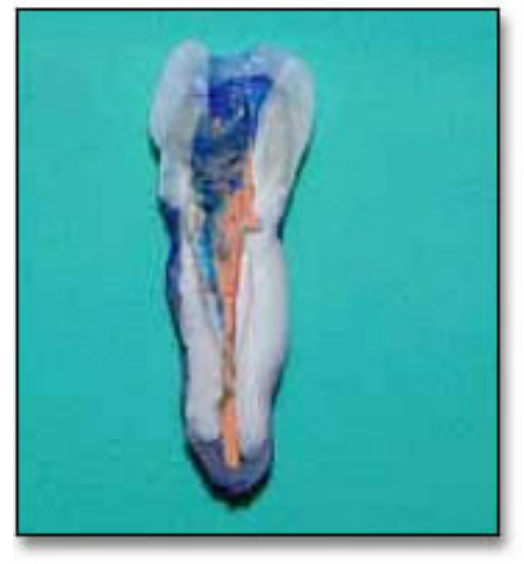

Figure 3. Dye penetration of laterial condensation group. 
be more homogenous, but in the Nd:YAG laser vertical thermoplasticized gutta-percha group at fragment junctions, there were carbonization areas at the impact points. According to the mean values, the lateral condensation group and the group tested with System-B showed less leakage then the group of laser-softened gutta-percha. Classic lateral condensation of the guttapercha is still one of the significant and popular techniques today. The apical leakage result for the lateral condensation of the gutta-percha of this study agrees with the results of the previous studies. $^{2}$ The Nd:YAG laser beam caused burning of the gutta-percha and root canal sealer, which were blackened at the impact points between the gutta-percha fragments. This carbonization-like part may cause an unsuitable condensation for the gutta-percha fragments.

Agreeing with Anic et al, the most leakage might be at the parts where the fragments contact with each other. ${ }^{12}$ In conclusion, the carbonization-like effect may change the physical and chemical properties of the root-canal sealer and gutta-percha, which may prevent fusion of the gutta-percha fragments. ${ }^{2,3}$

Anic et al. compared the sealing ability of lowtemperature gutta-percha thermoplasticized with Argon, CO2 and Nd: YAG laser. ${ }^{2}$ In their study they found similar results as burning points of gutta-percha and sealer treated with Nd:YAG laser. They state that Argon and partial CO2 lasers are more suitable for softening the guttapercha fragments in the apical third of the root canal. ${ }^{10}$ However, they concluded that all threelaser devices were not acceptable for accomplishing complete root canal obturation.
Although there was no statistically significant difference among the groups, the System-B thermoplasticized group showed less leakage than the others, creating a homogenous mass. Davalou et al. reported there were no significant differences between the apical and coronal sealing ability of System-B and microseal techniques. ${ }^{15}$ Techniques that thermoplasticize gutta-percha under controlled temperature applications such as System-B and microseal techniques may be suitable for clinic use with their short and simple manipulations.

Obturation of the anatomical irregularities in the root canals, such as lateral or accessory canals, may be important for the success of endodontic treatment since they are potential pathways for leakage to occur. In this study the thermoplastic obturation technique was effective in filling the canal irregularities shown in other reports. ${ }^{2,3,15}$ It showed a suitable condensation of gutta percha in root canal curvatures as well as adopting the root canal sealer to the root canal wall. Kytridou et al. reported the same results in their previous study. ${ }^{4}$

\section{Conclusion}

A root filling comprised primarily of gutta-percha is regarded as ideal (Schilder 1967 Langenol 1974). Silver et al. reported that System-B technique resulted in root filling with a percentage of gutta-percha above $90 \%$ at all levels. ${ }^{15}$

The results of this study showed that lateral condensation, thermoplasticized, and laser softened gutta-percha techniques were equally effective in restricting apical dye penetration. But in practice it is simpler to use the System-B technique instead of an Nd:YAG laser because of its difficult use, long working time, and high cost. 


\section{References}

1. Alaçam T. Endodonti. Ankara: Baris press; 2000:454-83

2. Anic I, Matsumato K. Comparison of the sealing ability of laser-softened, laterally condensed and low-temperature thermoplasticized gutta-percha. J Endod. 1995 Sep;21(9):464-9.

3. Davalous S, Guttmann JL, Nunn MH. Assessment of apical and coronal root canal seals using contemporary endodontic obturation and restorative materials and techniques. Int Endod J. 1999 Sep;32(5):388-96.

4. Baumgardner KR, Taylor J, Walton R. Canal adaptation and coronal leakage: lateral condensation compared to Thermafil. J Am Dent Assoc. 1995 Mar;126(3):351-6.

5. Greene HA, Wong M, Ingram TA 3rd. Comparison of the sealing ability of four obturation techniques. J Endod. 1990 Sep;16(9):423-8.

6. Farge $\mathrm{P}, \mathrm{Nahas} \mathrm{P}$, Bonin P. In vitro study of a Nd:YAP laser in endodontic retreatment. J Endod. 1998 May;24(5):359-63.

7. Fegan SE, Steiman HR. Comparative evaluation of the antibacterial effects of intracanal Nd:YAG laser irradiation: an in vitro study. J Endod. 1995 Aug;21(8):415-7.

8. Koba K, Matsumoto K, Kimura Y, et al. A histopathological study of the effects of pulsed Nd:YAG laser irradiation on infected root canals in dogs. J Endod. 1999 Mar;25(3):151-4.

9. Jukic S, Anic I, Koba K, et al. The effect of pulpotomy using CO2 and Nd:YAG lasers on dental pulp tissue. Int Endod J. 1997 May;30(3):175-80.

10 .Anic I, Segovic S, Katenec D, et al. Scanning electron microscopic study of dentin lased with argon, CO2, and Nd:YAG laser. J Endod. 1998 Feb;24(2):77-81.

11. Buchanan LS. The continuous wave of obturation technique: 'centered' condensation of warm gutta percha in 12 seconds. Dent Today. 1996 Jan;15(1):60-2, 64-7. No abstract available.

12. Zhang $\mathrm{C}$, Kimura $\mathrm{Y}$, Matsumoto $\mathrm{K}$, et al. Effects of pulsed Nd:YAG laser irradiation on root canal wall dentin with different laser initiators. J Endod. 1998 May;24(5):352-5.

13. Lares C, elDeeb ME. The sealing ability of the Thermafil obturation technique. J Endod. 1990 Oct;16(10):474-9.

14. Silver Gk, Love RM, Purton DG. Comparison of two vertical condensation obturation techniques: Touch 'n Heat modified and System B. Int Endod J. 1999 Aug;32(4):287-95.

15. Hata G, Kawazoe S, Toda T, et al. Sealing ability of Thermafil with and without sealer. J Endod. 1992 Jul;18(7):322-6. 

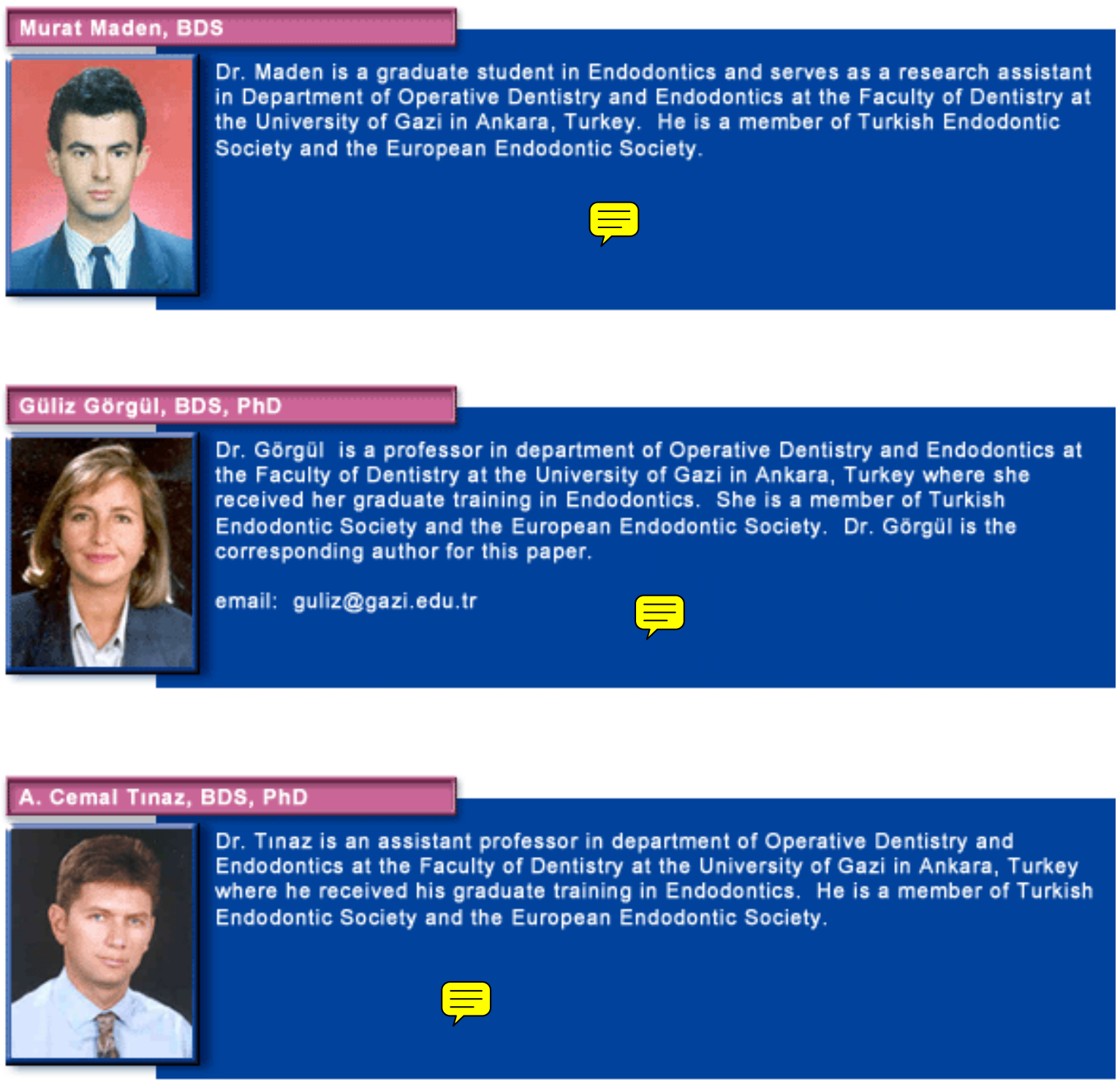